Вісник Дніпропетровського університету. Біологія. Екологія. - 2009. - Вип. 17, т. 1. - С. 51-56.

Visnyk of Dnipropetrovsk University. Biology. Ecology. - 2009. - Vol. 17, N 1. - P. 51-56.

УДК 631.416.8:504.53

В. В. Грушка, С. М. Сердюк

Днепропетровский национальный университет им. Олеся Гончара

\title{
САНИТАРНО-ГИГИЕНИЧЕСКАЯ И ЭКОЛОГО-ГЕОХИМИЧЕСКАЯ ОЦЕНКА ЗАГРЯЗНЕНИЯ ТЯЖЕЛЫМИ МЕТАЛЛАМИ ГОРОДСКИХ ПОЧВ НА ПРИМЕРЕ Г. ЖЕЛТЫЕ ВОДЫ
}

Визначено фактичний вміст важких металів у грунтах м. Жовті Води (Дніпропетровська область). Виявлено основні джерела забруднення грунтів. Оцінено ступінь забруднення важкими металами грунтового покриву. Запропоновано для використання перелік заходів з оптимізації стану міського середовища.

\author{
V. V. Grushka, S. M. Serdyuk \\ Oles' Gonchar Dnipropetrovsk National University
}

\section{SANITARY-HYGENIC AND ECOLOGY-GEOCHEMICAL ESTIMATION OF CONTAMINATION BY HEAVY CITY SOIL METALS FOR EXAMPLE OF CITY JOVTI VODY}

\begin{abstract}
An actual content of heavy metals in urban soils was determined. The basic sources of the city soils contamination was founded. The degree of ground cover contamination by heavy metals was appraised for the city of Zhovti Vody. The list of optimization measures is offered for the city environment.
\end{abstract}

\section{Введение}

С ростом индустриализации увеличивается спектр воздействий разнообразных промышленных выбросов на природные комплексы. Отходами различных производств загрязняются атмосфера, почва, вода, что влечет за собой изменение растительного и животного мира. Одними из наиболее опасных для биоты являются тяжелые металлы, обладающие канцерогенными и мутагенными свойствами. Их список включает в себя $\mathrm{As}, \mathrm{Cd}, \mathrm{Hg}, \mathrm{Pb}, \mathrm{Se}, \mathrm{Zn}$ и др. Известно, что в результате различных природных превращений данные техногенные элементы могут широко распространяться и активно мигрировать в природных компонентах Земли [15]. Почва является одним из основных концентраторов тяжелых металлов в биосфере. К актуальным задачам контроля за использованием природных ресурсов относится управление процессами самовозобновления почв, которые являются незаменимым компонентом биосферы и совместно с растительными организмами определяют ее устойчивое функционирование [13; 14].

В отличие от других поллютантов, способных разлагаться под действием физико-химических и биологических факторов или выводиться из почвы, тяжелые металлы сохраняются в ней длительное время даже после устранения источника загрязнения. Согласно современным научным исследованиям, период полуудаления тяжелых металлов из почв в условиях лизиметров (специальных приборов, изучающих внутрипочвенный сток) варьирует в зависимости от вида металлов: для $Z n-70-510$ лет, $C d-13-$ $1100, C u-310-1500, P b-740-5900$ лет. Детоксикация почв, загрязненных тяжелыми 
металлами, имеет определенные трудности. Их накопление в почве нарушает физикохимическое равновесие природной системы и дает толчок ряду процессов, действующих на почвенные свойства $[2 ; 16]$. Помимо прямого токсического воздействия, появления физиологических и функционально-морфологических отклонений, роста общей заболеваемости, характерны и отдаленные эффекты, затрагивающие основополагающие функции живых существ: воспроизводство и биопродуктивность, генеративную способность и смертность. Угроза создается не только для отдельных особей, но и для целых популяций и поколений [7; 17]. Подобного рода исследования актуальны и важны для всех промышленных центров Украины.

\section{Материал и методы исследований}

Желтые Воды - индустриальный город в западной части Днепропетровской области. Его территория (33 км²) практически со всех сторон окружена экологически опасными производствами и объектами, деятельность которых связана с загрязнением почвы и других природных компонентов. Главными источниками загрязнения окружающей среды города являются: шахта Новая, сернокислотный завод, гидрометаллургический завод, городская теплоэлектроцентраль, хвостохранилища гидрометаллургического завода в карьере бурых железняков и в балке Щ. Основным предприятием города является Восточный горно-обогатительный комбинат. Его специализацией является добыча и обогащение урановых руд. Добыча осуществляется в Кировоградской области (Смолинское месторождение), а обогащение - непосредственно в Желтых Водах на гидрометаллургическом заводе.

В городе ранее проводились исследования, касающиеся радиационного загрязнения (отчет изыскательного отряда ПромНИИпроект, Желтые Воды, 2004). При этом площадная оценка содержания тяжелых металлов в жизнеобеспечивающих средах на территории г. Желтые Воды комплексно не проводилась. А рассмотрение такого рода вопросов является не менее важным, поскольку почва - многолетний индикатор загрязнения окружающей среды тяжелыми металлами. Таким образом, изучение загрязнения тяжелыми металлами городской территории (в т. ч. почв) актуально и необходимо. Преимущественными типами почв являются степные черноземы обыкновенные, которые сформировались в условиях непромывного типа водного режима под разнотравно-типчаково-ковыльной растительностью. По данным агропочвенного районирования, территория города расположена в пределах степной черноземной зоны, подзоны северной степи черноземов обыкновенных Правобережно-Днепровской умеренноконтинентальной провинции черноземов обыкновенных.

Формирование современных почв осуществляется в тесной взаимосвязи с геоморфологической структурой и геологическими особенностями территории. На территории района исследования основную часть занимают водоразделы и склоны, покрытые почвами черноземного типа. Эти почвы составляют основной фонд пахотных земель на окраинах города. В условиях различной крутизны склонов выделяют черноземы, которые отличаются по степени смытости от слабо до сильно смытых и, как следствие этого, черноземы намытые. Схема почвенного профиля представлена на рисунке 1.

Горизонт А (0-40 см) черного цвета комковато-зернистый, сильно переплетенный корнями. Горизонт АВ (40-65 см) - темно-серый с буроватым оттенком, сильно суглинистый, зернисто-мелковатый, ниже - комковатый, рыхлый, слабо уплотненный, на сухой стенке почвенного разреза появляется карбонатный мицелий. Закипает от $10 \% \mathrm{HCl}$ начиная с 55 см (отчет изыскательского отряда ПромНИИпроект). Горизонт Вса (65-120 см) - сероватый, слабо, но равномерно гумусный, суглинистый, призмо- 
подобно-комковатый, уплотненный, одиночная кротовина, переход постепенный. Горизонт Сса $(120$ см) - материнская порода - тяжелый лессовидный суглинок, до 160 см буроватый, глубже - одиночная карбонатная «белоглазка». Граница расположения «белоглазки» указывает на глубину промачивания почв осадками. Так, в районе г. Желтые Воды горизонт «белоглазка» расположен на глубине 90-170 см, то есть почвы промачиваются до этой глубины (отчет изыскательского отряда ПромНИИпроект). Подобный тип почв (черноземы обыкновенные) способствует накоплению тяжелых металлов в верхних горизонтах.

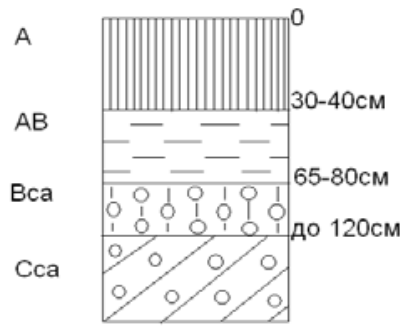

\author{
Рис. 1. Почвенный профиль \\ чернозема обыкновенного \\ (территория г. Желтые Воды)
}

Сбор и анализ фактического материала (проб почв) производился согласно стандартным методикам [1]. Из горизонта 0-10 см на целине и 0-20 см - на газонах. Пробы отбирали в разных функциональных зонах (на территории промышленной застройки, рекреационной и селитебной зон) города с целью прослеживания миграции и динамики загрязнения тяжелыми металлами почв. Лабораторный анализ проб почв производился методом атомно-абсорбционной спектрофотометрии. Определено валовое содержание тяжелых металлов ( $\mathrm{Mn}, \mathrm{Cu}, \mathrm{Zn}, \mathrm{Ni}, \mathrm{Cd}, \mathrm{Pb})$ в отобранных образцах [6].

Фактическое содержание тяжелых металлов в почвах не дает возможности анализировать степень загрязнения территории города. Для анализа и сравнения использовались региональные кларки тяжелых металлов в почвах степной зоны Украины, разработанные лабораторией охраны почв от загрязнения Института почвоведения и агрохимии им. А. Н. Соколовского [7] для $\mathrm{Mn}, \mathrm{Cu}, \mathrm{Zn}, \mathrm{Ni}, \mathrm{Pb}$ (мг/кг):

$$
M n \frac{670}{200-1600} ; C u \frac{27}{10-64} ; Z n \frac{62}{33-100} ; N i \frac{25}{19-40} ; P b \frac{13}{10-15} ; C d-0,6 .
$$

Для определения степени загрязнения почвенного покрова той или иной части города использовался суммарный показатель концентраций (СПК), который выражался отношением фактической концентрации загрязнителя к фоновой концентрации этого элемента в почвах для степной зоны Украины. В качестве фонового показателя использовалось наименьшее значение регионального содержания тяжелых металлов в почве. Согласно ранее разработанной методике и классификации [10], почвы по содержанию в них тяжелых металлов можно разделить на: СПК $<8$ - практически чистые, 8-16 - слабозагрязненные, 16-32 - среднезагрязненные, 32-64 - сильнозагрязненные, 64-128 - очень сильнозагрязненные, СПК > 128 - максимально загрязненные.

Не менее важным показателем является предельно допустимая концентрация, которая отражает степень влияния загрязненных почв непосредственно на человека. Превышение ПДК может вызывать различные группы заболеваний у населения, проживающего на загрязненных территориях. Для тяжелых металлов в почвах [5] определены следующие ПДК (мг/кг): $M n-1500, C u-55, Z n-100, N i-85, P b-32$.

Статистическая обработка данных осуществлялась по стандартным методикам [4]. 


\section{Результаты и их обсуждение}

Превышение фактического содержания тяжелых металлов почв Желтых Вод над фоновыми значениями (табл. 1) присуще таким элементам как $\mathrm{Mn}, \mathrm{Cu}, \mathrm{Zn}, \mathrm{Ni}, \mathrm{Pb}, \mathrm{Cd}$. Наибольшая концентрация $M n(1205,5$ мг/кг) и $N i(215,6$ мг/кг) наблюдается на территории сернокислотного и гидрометаллургического заводов, что объясняется спецификой производства. Также значительное содержание $M n$ в почве отмечается на территориях селитебной застройки (ул. 50-летия Комсомола, Б. Хмельницкого, Кропоткина) и Детского парка, как следствие примыкания к главным автодорогам города.

Таблий 1

Загрязнение тяжелыми металлами почв г. Желтые Воды

\begin{tabular}{|c|c|c|c|c|c|c|c|c|c|c|c|c|}
\hline \multirow{2}{*}{ Точки пробоотбора } & \multicolumn{2}{|c|}{$M n$} & \multicolumn{2}{|c|}{$\mathrm{Cu}$} & \multicolumn{2}{|c|}{$Z n$} & \multicolumn{2}{|c|}{$\mathrm{Ni}$} & \multicolumn{2}{|c|}{$\mathrm{Pb}$} & \multicolumn{2}{|c|}{$C d$} \\
\hline & $\mathrm{M \Gamma} / \mathrm{K} \Gamma$ & $K c_{M n}{ }^{*}$ & $\mathrm{M \Gamma} / \mathrm{K} \Gamma$ & $K c_{C u}$ & $\mathrm{M \Gamma} / \mathrm{K} \Gamma$ & $K c_{Z n}$ & $\mathrm{M \Gamma} / \mathrm{K} \Gamma$ & $K c_{N i}$ & $\mathrm{MT} / \mathrm{KT}$ & $K c_{P b}$ & $\mathrm{M \Gamma} / \mathrm{K} \Gamma$ & $K c_{C d}$ \\
\hline $\begin{array}{l}\text { Серноки } \\
\text { (террито }\end{array}$ & 1205,49 & 6,03 & 18,35 & 1,83 & 16,75 & 0,51 & 33,81 & 1,78 & 7,93 & 0,79 & 1,07 & 1,78 \\
\hline $\begin{array}{l}\text { Сернокислотный завод } \\
\text { (санитарно-защитная зона) }\end{array}$ & 279,55 & 1,40 & 6,12 & 0,61 & 10,55 & 0,32 & 15,18 & 0,80 & 8,11 & 0,81 & 1,60 & 2,67 \\
\hline Парк им. Б. Хмельницкого & 357,19 & 1,79 &, 61 & 0,96 & 12,29 & 0,37 & 21,48 & 1,13 & 9,86 & 0,99 & 0,66 & 1,11 \\
\hline $\begin{array}{l}\text { Гидрометаллургический } \\
\text { завод (санитарно- } \\
\text { защитная зона) }\end{array}$ & 694,70 & 3,47 & 9,02 & 0,90 & 51,17 & 1,55 & 46,93 & 2,47 & 14,45 & 1,44 & 1,99 & 3,32 \\
\hline $\begin{array}{l}\text { Пересечение ул. Кропот- } \\
\text { кина и ул. 50-летия Ком- } \\
\text { сомола }\end{array}$ & 740,05 & 3,70 & 7,98 & 0,80 & 16,83 & 0,51 & 59,95 & 3,16 & 6,84 & 0,68 & 1,11 & 1,84 \\
\hline $\begin{array}{l}\text { Балка возле п } \\
\text { (низовье) }\end{array}$ & 264,33 & 1,32 & 7,68 & 0,77 & 12,07 & 0,37 & 122,55 & 6,45 & 7,04 & 0,70 & 0,71 & 1,18 \\
\hline $\begin{array}{l}\text { Гидрометалј } \\
\text { завод (терри }\end{array}$ & 836,26 & 4,18 & 8,99 & 0,90 & 28,84 & 0,87 & 77,98 & 4,10 & 11,04 & 1,10 & 2,30 & 3,83 \\
\hline $\begin{array}{l}\text { Балка возле пляжа } \\
\text { (верховье) }\end{array}$ & 540,55 & 2,70 & 8,36 & 0,87 & 12,93 & 0,39 & 27,70 & 1,46 & 7,77 & 0,78 & 1,74 & 2,91 \\
\hline $\begin{array}{l}\text { Городск } \\
\text { венный }\end{array}$ & 611,64 & 3,06 & 7,35 & 0,74 & 13,57 & 0,41 & 21,42 & 1,13 & 11,59 & 1,16 & 1,56 & 2,60 \\
\hline $\begin{array}{l}\text { Пойма р. Желтая } \\
\text { (верховье) }\end{array}$ & 122,02 & 0,61 & 4,17 & 0,42 & 21,54 & 0,65 & 21,64 & 1,14 & 7,78 & 0,79 & 1,57 & 2,62 \\
\hline Детский парк & 711,42 & 3,56 & 13,86 & 1,39 & 16,84 & 0,51 & 91,27 & 4,80 & 10,45 & 1,05 & 0,84 & 1,40 \\
\hline $\begin{array}{l}\text { Персечение ул. 50-летия } \\
\text { Комсомола и ул. Гагарина }\end{array}$ & 707,53 & 3,54 & 6,01 & 0,60 & 18,77 & 0,57 & 215,64 & 11,35 & 8,45 & 0,85 & 1,52 & 2,54 \\
\hline Пойма р. Желтая (низовье) & 517,57 & 9 & 5,60 & 0,56 & 5,70 & 0,48 & 23,75 & 1,25 & 8,38 & 0,84 & 1,24 & 2,07 \\
\hline $\begin{array}{l}\text { Пересечение } \\
\text { ул. Б. Хмельницкого } \\
\text { и ул. Франко }\end{array}$ & 778,12 & 3,90 & 5,88 & 0,59 & 13,81 & 0,42 & 70,64 & 3,72 & 8,22 & 0,82 & 2,16 & 3,60 \\
\hline $\begin{array}{l}\text { Городской пляж } \\
\text { (искусственный водоем) }\end{array}$ & 121,44 & 0,61 & 5,02 & 0,50 & 6,05 & 0,18 & 21,43 & 1,13 & 6,15 & 0,62 & 0,54 & 0,91 \\
\hline
\end{tabular}

Примечание: * $K c_{i}-$ коэффициент концентрации (отношение содержания химического элемента в почве к его фоновому содержанию).

Максимальное содержание $N i$ в почве отмечено на селитебной территории ул. 50-летия Комсомола - как следствие существенной здесь автотранспортной нагрузки, плотной застройки, которая значительно снижает рассеяние загрязнителей в атмосферном воздухе. Фактическая концентрация $C d$ (от 0,66 до 2,30 мг/кг) в почвах города, превышающая фоновое содержание, зафиксирована во всех точках исследования.

Относительно высокие значения суммарного показателя концентраций наблюдаются на территории гидрометаллургического $(10,00$, наибольшую концентрацию имеет $M n)$ и сернокислотного заводов $(7,73)$, селитебной застройки в районе 54 
ул. Б. Хмельницкого $(8,04)$. Почвенный покров этих районов можно отнести к слабозагрязненным. Наибольшее значение суммарного показателя концентраций отмечается в почвах селитебной застройки в районе ул. 50-летия Комсомола $(14,44)$. Таким образом, можно выделить территории города с наибольшей степенью загрязнения почвенного покрова тяжелыми металлами: гидрометаллургический завод, селитебная зона в районе ул. 50-летия Комсомола.

Точки пробоотбора в исследуемых почвах г. Желтые Воды (табл. 2) сгруппированы в зависимости от функционального назначения территории: промышленной, селитебной, рекреационной. Высокое содержание $M n$ зарегистрировано в промышленной зоне города. После обогащения урановых руд на гидрометаллургическом заводе образуется «пустая» порода. По-видимому, концентрация марганца в ней имеет существенно высокое значение и обогащает тем самым близлежащие территории.

Ассоциации тяжелых металлов в почвах г. Желтые Воды

Таблиия 2

\begin{tabular}{|l|c|c|c|c|}
\hline \multirow{2}{*}{ Зона города } & \multicolumn{3}{|c|}{ Ряды относительной концентрации тяжелых металлов в почвах } \\
\cline { 2 - 5 } & $\mathrm{n} \bullet 1000$ & $\mathrm{n} \bullet 100$ & $\mathrm{n} \bullet 10$ & $\mathrm{n} \bullet 1$ \\
\hline Промышленная & $\mathrm{Mn}$ & $\mathrm{Mn}$ & $\mathrm{Cu}, \mathrm{Zn}, \mathrm{Ni}, \mathrm{Pb}$ & $\mathrm{Cu}, \mathrm{Pb}, \mathrm{Cd}$ \\
\hline Селитебная & - & $\mathrm{Mn}, \mathrm{Ni}$ & $\mathrm{Zn}, \mathrm{Ni}$ & $\mathrm{Cu}, \mathrm{Pb}, \mathrm{Cd}$ \\
\hline Рекреационная & - & $\mathrm{Mn}, \mathrm{Ni}$ & $\mathrm{Cu}, \mathrm{Zn}, \mathrm{Ni}, \mathrm{Pb}$ & $\mathrm{Cu}, \mathrm{Zn}, \mathrm{Pb}, \mathrm{Cd}$ \\
\hline
\end{tabular}

В пределах сернокислотного завода наблюдается повышенная кислотность почв (Отчет изыскательского отряда ПромНИИпроект) за счет технологического выброса кислотных компонентов. При изменении величины $p H$ разрушается почвенный поглощающий комплекс, нарушаются микробиологические процессы. В результате разрушения структуры ухудшается водно-воздушный режим, уменьшается крнцентрация почвенного гумуса, и в конечном итоге почва теряет плодородие.

Поведение рассматриваемых тяжелых металлов во многом зависит от $p H$ почв. Цинк и кадмий наиболее подвижны в кислых почвах. Растворимость марганца и никеля имеет наибольшие значения в почвах с повышенной кислотностью [2]. Таким образом, рассматриваемые элементы в данных условиях являются активными мигрантами, что и подтверждается данными таблицы 2. Наличие высоких концентраций тяжелых металлов в почвенном покрове рекреационной зоны объясняется орографией местности (низменное положение).

При оценке влияния тяжелых металлов на человека необходимо сопоставить установленные ПДК этих металлов с фактическим содержанием их в почвах. Среди рассмотренной группы тяжелых металлов зафиксировано незначительное превышение ПДК никеля, которое наблюдается в районе балки вблизи пляжа (в 1,44 раза) и на селитебной застройке - ул. 50-летия Комсомола (в 2,54 раза). Такая фактическая концентрация $\mathrm{Ni}$ $(215,64$ мг/кг) в почвах оказывает негативное влияние на состояние здоровья населения г. Желтые Воды. Согласно детальным медико-экологическим исследованиям [3; 9] у населения этих районов можно ожидать поражения центральной и периферической нервной системы, органов внутренней секреции, развития раковых новообразований, негативного влияния на репродуктивную функцию, нарушения аппарата наследственности [12]. Это усугубляется целым рядом других негативных техногенных факторов.

\section{Выводы}

Основными загрязняющими элементами почв города являются $M n$ (III класс опасности), $N i$ (II класс опасности), $C d$ (І класс опасности). По суммарному показателю концентраций выделены территории со слабозагрязненным почвенным покровом. Наи- 
большее суммарное загрязнение почв отмечается на селитебной застройке в районе ул. 50 -летия Комсомола $(14,44)$. Фактическое содержание $N i$ в почвах превышает ПДК на селитебной застройке в районе ул. 50-летия Комсомола и в балке вблизи городского пляжа. Для улучшения экологической обстановки города, с учетом выявленных геохимических аномалий, необходимо проводить ряд оптимизационных мероприятий (рекультивацию загрязненных территорий, создание рационального потока автотранспорта, строительство объездных дорог для транзитного транспорта).

\section{Библиографические ссылки}

1. Беккер А. А. Охрана и контроль загрязнения природной среды / А. А. Беккер, Т. Б. Агаев. Л. : Гидрометеоиздат, 1989. -286 с.

2. Кабата-Пендиас А. Микроэлементы в почвах и растениях / А. Кабата-Пендиас, Х. Пендиас. М. : Мир, 1989. -439 c.

3. Кораблева А. И. Введение в экологическую токсикологию / А. И. Кораблева, Л. Г. Чесанов, А. Г. Шапарь. - Д. : Центр экологического образования, 2001. - 300 с.

4. Лакин Г. Ф. Биометрия. - М. : Высшая школа,1980. - 295 с.

5. Мазур И. И. Инженерная экология. Общий курс в 2 томах / И. И. Мазур, О. И. Молдаванов, В. Н. Шишов. - Т. 2. - М. : Высшая школа, 1996. -655 с.

6. Методи аналізів грунтів і рослин / За ред. С. Ю. Булигіна. - Х. : УААН, 1999. - 156 с.

7. Пасічний Г. В. Геоекологічні моніторингові дослідження вмісту важких металів у грунтах техногенно змінених ландшафтів (на прикладі м. Дніпродзержинська) / Г. В. Пасічний, С. М. Сердюк // Вісник Дніпропетр. ун-ту. Геологія. Географія. - 2002. - Вип. 4. - С. 161-166.

8. Смирнова Р. С. Система геохимических показателей для оценки состояния окружающей среды при разработке территориальных комплексных схем охраны природы городов / Р. С. Смирнова, Б. А. Ревич // Биогеохимические методы при изучении окружающей среды. М. : ИМГРЭ, 1989. $-228 \mathrm{c}$.

9. Тяжелые металлы внешней среды и их влияние на репродуктивную функцию женщин / А. М. Сердюк, Э. Н. Белицкая, Н. М. Паранько, Г. Г. Шматков. - Д. : Арт-Пресс, 2004. - 148 с.

10. Фоновий вміст важких металів у грунтах України / Інститут грунтознавства та агрохімії ім. О. Н. Соколовського / За ред. А. І. Фатєєва. - Х., 1997. - 275 с.

11. Фоновий вміст мікроелементів у грунтах України / А. І. Фатєєв, Я. В. Пащенко, С. А. Балюк та ін. / За ред. А. І. Фатєєва, Я. В. Пащенко. - Х., 2003. - 120 с.

12. Экология и охрана биосферы при химическом загрязнении / И. Н. Лозановская и др. - М. : Высшая школа, 1998. - 287 с.

13. Экология и охрана биосферы при химическом загрязнении / Д. С. Орлов, Л. К. Садовникова, И. Н. Лозановская. - М. : Высшая школа, 2002. - 358 c.

14. Helmisaari H.-S. Spatial and age-related variation in nutrient concentrations of Pinus sylvestris needles // Silva Fennica. - 1992. - Vol. 26. - N 3. - P. 145-153.

15. Helvey G. D. A summary of rainfall interception by certain conifers of North America // Biological effects in the hydrological cycle. - Washington, USA, 1971. - P. 103.

16. Pathways of atmospheric metal elements deposited in forests / Zhi-Qing Lin, P. H. Schuepp, N. N. Barthakur et al. // Contaminated soils. III International conference on the biogeochemistry of trace elements. Theme C : Evaluation and management of risk. - Paris, France, 1995.

17. Smith W. H. Lead contamination of the roadside ecosystem // Air Pollution Control Associated. 1976. - Vol. 26. - P. 753.

Надійшла до редколегї̈ 25.03.2009 